\title{
EL VALLE CALCHAQUÍ MEDIO (SALTA, ARGENTINA) DURANTE LOS SIGLOS XV-XVII: APORTES DESDE EL REGISTRO ARQUEOLÓGICO Y LAS FUENTES DOCUMENTALES*
}

\author{
THE MIDDLE CALCHAQUI VALLEY (SALTA, ARGENTINA) DURING \\ THE CENTURIES 15TH AND 17TH: CONTRIBUTIONS FROM THE \\ ARCHAEOLOGICAL REGISTER AND THE DOCUMENTARY SOURCES
}

\author{
María Cecilia Castellanos**
}

\begin{abstract}
Las quebradas occidentales del valle Calchaquí medio (actual provincia de Salta, Argentina) jugaron un papel importante en la dinámica regional. Nexos naturales de conexión con otros ambientes como el de puna, quebradas como las de Gualfín, Tacuil y Luracatao, constituyeron espacios aptos para el asentamiento de poblaciones. Fuentes documentales mencionan que hacia los siglos XVI y XVII este sector constituía un espacio multiétnico, con poblaciones que conformaban unidades sociopolíticas fragmentadas. Es precisamente aquí, hacia el interior de las quebradas altas, donde se ubican poblados defensivos en altura (pukara), asociados a recintos bajos y a grandes extensiones agrícolas. Las investigaciones arqueológicas desarrolladas en estos poblados permiten plantear una continuidad de ocupación, por lo menos desde el siglo XI al XVII. En el marco de un proyecto general y tomando en cuenta los trabajos desarrollados por el equipo de investigación en donde se incluye esta propuesta, se aporta información acerca del sector medio del valle Calchaquí, tomando un lapso temporal que abarca los siglos XV-XVII. Se trabajan diversos indicadores en el paisaje (como los poblados defensivos o pukara) agregando además información producida por investigaciones arqueológicas y datos mencionados en fuentes históricas.
\end{abstract}

Palabras claves: Valle Calchaquí Medio, quebradas altas, pukara, siglos XV-XVII.

The western gorges of the middle Calchaqui Valley (the current province of Salta, Argentina) took an important role in the regional dynamic. Natural ways linked with other environments as the Puna and gorges as Gualfil, Tacuil and Luracatao composed suitable spaces for the populations settlements. Documentary sources mention that during the 15th and the 17th centuries, this area was part of a multiethnic space, with populations which made up fragmented sociopolitical units. That is exactly, within the high gorges, where pukaras are located. They are associated with low enclosures and vast agricultural areas. The archaeological reseachs developed in those populations allowed us to indicate a continuing occupation; at least, from the 11th to the 17th century. In the context of a general project (where this work is included) and taking into account all the works developed by the research team, information about the middle Calchaqui Valley is provided. It is taken into account a temporary period from the 15th to the 17th century. Different indicators in the landscape are worked (as the pukaras), also it is added information produced by archaeological researchs and datum mentioned in historical sources.

Key words: middle Calchaquí Valley, high gorges, pukara, 15th-17th centuries.

\section{Introducción}

En esta oportunidad nos proponemos aportar nueva información acerca del valle Calchaquí a partir de la integración de datos provenientes de dos fuentes: el registro arqueológico y las fuentes documentales. Nos planteamos discutir cuestiones vinculadas al uso del espacio y al papel que tuvieron algunas poblaciones localizadas en el sector medio del valle, durante los momentos previos al arribo español a la zona (siglo XV) y hasta fines del siglo XVII. Situándonos en el espacio geográfico, el área de trabajo toma en cuenta las quebradas altas de Angastaco y Molinos, y sectores del valle de Luracatao y Amblayo, en los departamentos de Molinos y San Carlos, actual provincia de Salta, Argentina.

Consideramos que los momentos inmediatamente anteriores al siglo XVI son fundamentales para comprender procesos posteriores. Específicamente tomamos un lapso entre los siglos XV y XVII partiendo

\footnotetext{
* Resultado proyecto: PICT 2007 No 015500 FONCYT y AGENCIA PICT 2013 No 0042.

** Universidad Nacional de Salta, Facultad de Humanidades. ICSOH-CONICET, Salta, Argentina. Correo electrónico: cecicastellan88@yahoo.com.ar
} 
de tres ejes organizativos: territorio, tiempo y poblaciones. Respecto del territorio, desde la arqueología, tomamos en cuenta diversos indicadores en el paisaje, como los asentamientos de tipo pukara ${ }^{1}$, sitios ubicados en cotas más bajas, terrazas y andenes, arte, santuarios y ofrendatorios y la cultura material que da cuenta de diversas ocupaciones a nivel espacial y temporal. A ello le sumamos información mencionada en las fuentes documentales editadas (trabajos de Lorandi y Boixadós 1987-1988, Larrouy 1923) e inéditas para la zona (títulos de encomiendas, cartas de gobernadores localizadas en repositorios del AGI y $\mathrm{ABNB})^{2}$.

En primer lugar realizamos una breve reseña acerca del uso del territorio en el Calchaquí durante momentos Tardíos o Período de Desarrollos Regionales (en adelante PDR). Los planteos tradicionales señalan que durante el mismo las poblaciones locales se estructuraban bajo organizaciones de tipo jefaturas con marcada desigualdad social y estratificación político-económica institucionalizada (Tarragó 2000). Nuevos planteos sugieren otras posibilidades respecto de las poblaciones tardías desde la integración comunal (Acuto 2007) y el corporativismo (Nielsen 2004), cuestionando el modelo de jefatura tradicional.

\section{Punto de partida}

Partimos de la idea que la percepción y ordenamiento del espacio es propia de cada sociedad y de cada tiempo (Sica 2003). Los territorios, entonces, serán significados, construidos y vividos de diferentes maneras según los sujetos y el contexto en el que se hallan insertos. Consideramos además que las diferentes maneras en que se experimentan y viven los espacios a lo largo del tiempo involucran no solo acciones o modos de habitar los mismos, sino también relaciones que puedan surgir de la relación entre sujetos, objetos, elementos naturales, etc. Desde este enfoque, diferentes elementos pueden ser manipulados para que participen activamente en la producción y reproducción de espacios y temporalidades, formando parte también en procesos de construcción o mantenimiento de memorias y territorios (Piazzini Suárez 2006)

La disposición espacial de los asentamientos tardíos registrados en la zona permite sugerir la hipótesis de una integración poblacional de manera transversal, vinculada al acceso a territorios de importante productividad agrícola y recursos económicos disímiles (Baldini y De Feo 2000).
El dominio español implicó una nueva forma, respecto de la local, de pensar la espacialidad y de materializarla, siguiendo otra lógica diferente a la indígena. El territorio comenzó a tener límites y demarcaciones geográficas y jurídicas, además de nominales. Esto tuvo como fin poder realizar un ordenamiento a nivel geográfico en los territorios y poblaciones por controlar. Ante esto, es importante también tener en cuenta que las percepciones, nominaciones y categorías no son estáticas, por lo tanto debemos tener cuidado en no tomar los documentos como una fuente que permitirá contrastar la información en el terreno. Gabriela Sica (2003: 53) ya había destacado los problemas que se plantean a la hora de confrontar las fuentes, la cartografía y las diferentes percepciones históricas espaciales.

\section{Breve reseña relativa a la ocupación del NOA entre los siglos X a XVI}

El recorte temporal abordado abarca lo que en arqueología del Noroeste argentino (en adelante NOA) se conoce como PDR o Tardío (900 y 1400 d.C.) y la expansión Incaica (desde el 1400/30 d.C.). Desde un modelo evolucionista el PDR ha sido definido como un momento caracterizado por sociedades de tipo jefaturas con una marcada desigualdad a nivel social y una estratificación política, económica y social institucionalizadas. Se plantearon además la existencia de cambios a nivel social como el rápido incremento demográfico, la tendencia hacia la concentración de la población en conglomerados habitacionales, transformaciones económicas y en los circuitos de circulación de bienes, junto a momentos de importante tensión social y conflicto efectivo entre las poblaciones de los Andes Centro-Sur (Tarragó 2000, Nielsen 2003). Bajo este contexto de tensión social generalizada, Nielsen (2002) menciona la consolidación de estructuras de integración política supracomunitaria, cambios en las formas de apropiación de la tierra y de recursos estratégicos. Los especialistas coinciden en que para estos momentos uno de los indicadores arqueológicos del conflicto son los sitios defensivos o pukaras, asentamientos, en general, localizados en terrenos naturalmente defendidos y de difícil acceso, que en el actual territorio de Argentina se encuentran desde la Puna Jujeña hasta La Rioja (Ruiz y Albeck 1997). Trabajos realizados en estos sitios (por ejemplo en el área circuntiticaca en el territorio Colla así como en Lípez) apoyan las ideas 
de la ocupación continua de estos asentamientos (Arkush y Stanish 2005, Nielsen 2002).

La presencia Inca en el NOA implicó la reorganización de espacios, la resignificación y construcción de nuevos paisajes, como también la incorporación de nuevos significados y símbolos relacionados al estado Inca (Williams 2008). Esto sin duda tuvo que haber modificado las prácticas sociales y formas de vida local. Las estrategias de dominación o apropiación tomaron distintos matices. Dentro de estas, la conquista y el control simbólico o la "conquista ritual" pudo haber constituido una de las principales estrategias de dominación, utilizando la violencia de forma más limitada, pero más eficaz (Nielsen y Walker 1999). Desde una mirada espacial, la expansión inca hacia el actual NOA implicó un reordenamiento del espacio y de los territorios existentes. Lo que involucró además de una vinculación a partir de redes de caminos y postas, la delimitación de unidades administrativas en donde se emplazaban centros de poder político o económico (González 1980).

En el sector norte del valle Calchaquí se localizan grandes asentamientos incaicos con probable función administrativa, como Cortaderas y Potrero de Payogasta, además de otros de almacenaje y producción metalúrgica como Los Graneros y La Encrucijada. También se registraron en el valle troncal del Calchaquí sitios locales mixtos que presentan sectores arquitectónicos con componentes netamente incas como La Paya y Guitián (Acuto 1999, D'Altroy et al. 2000; entre otros).

\section{El sector medio del valle Calchaquí, una mirada desde la Arqueología}

El valle Calchaquí constituye un eje de circulación Norte-Sur muy importante en el actual noroeste argentino. Aquí las quebradas transversales funcionan como un espacio de conexión en sentido Este-Oeste relacionando diferentes pisos altitudinales $\mathrm{y}$ ambientes como yungas, valles mesotermales y puna (Lorandi y de Hoyos 1995).

Las investigaciones arqueológicas que se vienen desarrollando en el sector medio del valle, sobre las quebradas altas, permiten señalar que las mismas constituyeron espacios aptos para el asentamiento de poblaciones, ya que son espacios con humedad, protegidos de los vientos, fundamental para el desarrollo de una agricultura intensiva (Williams et al. 2011). Aquí los centros de producción y focos de población local parecen ubicarse al interior de las quebradas estrechas que comunican con la puna. Es en este sector donde se destaca la presencia de asentamientos de tipo pukara y de pequeños conjuntos de recintos diseminados en el fondo de valle (Williams y Villegas 2013). Los fechados radiocarbónicos que se tiene de asentamientos con diferente funcionalidad permiten sugerir ocupaciones que van desde el Formativo medio (Beta-232251: $1240 \pm 40$, Despedres de Quebrada Grande) hasta momentos coloniales (Beta-239860: 1412-1635, Tambo Angastaco) (Williams 2012).

\section{Poblaciones y asentamientos durante el Tardío o Período de Desarrollos Regionales (PDR)}

A partir de la ubicación espacial de los asentamientos en el sector medio del Calchaquí, Baldini y De Feo (2000) sugirieron la posibilidad que hacia el sur de Molinos las poblaciones habrían asumido un carácter más disperso. Además de ello, las fuentes tempranas señalan que para los siglos XVI y XVII este sector formaba parte del territorio Sicha con asentamiento en puestos, presumiblemente instalaciones pequeñas y no concentradas (Lorandi y Boixadós 1987-1988).

Las investigaciones realizadas en las quebradas altas de Gualfín y Tacuil han permitido localizar al menos diez pukaras distribuidos en una superficie de 149 ha. (Figura 1). De ellos, nueve presentan ocupación desde el tardío local (Fuerte Tacuil, Peña Alta, Fuerte Gualfín, Cerro La Cruz, Pueblo Viejo, El Alto, pukara de La Angostura, Peña Punta y Ellencot), y uno es de momentos incaicos (pukara de Angastaco). Los pukaras se localizan en sectores altos, naturalmente defendidos y superando en ocasiones los $200 \mathrm{~m}$ por sobre el nivel de fondo de valle (p.ej. Peña Alta), siendo algunos de ellos de acceso extremadamente difícil por una sola ruta que podía haber sido fácilmente defendida o bloqueada (p.ej. Peña Alta, Fuerte Tacuil y Pueblo Viejo) (Cremonte y Williams 2007, Villegas 2006). La localización de los pukaras en este sector del valle, junto a su disposición e intervisibilidad, permitió plantear la hipótesis de que, en caso de ser contemporáneos entre sí, podrían haber estado ligados al control del territorio y de la circulación de personas, objetos y materias primas o recursos (Villegas 2011, Williams et al. 2005). Williams (2010) destaca la polifuncionalidad de estos sitios y el papel relevante de los mismos en el PDR, 


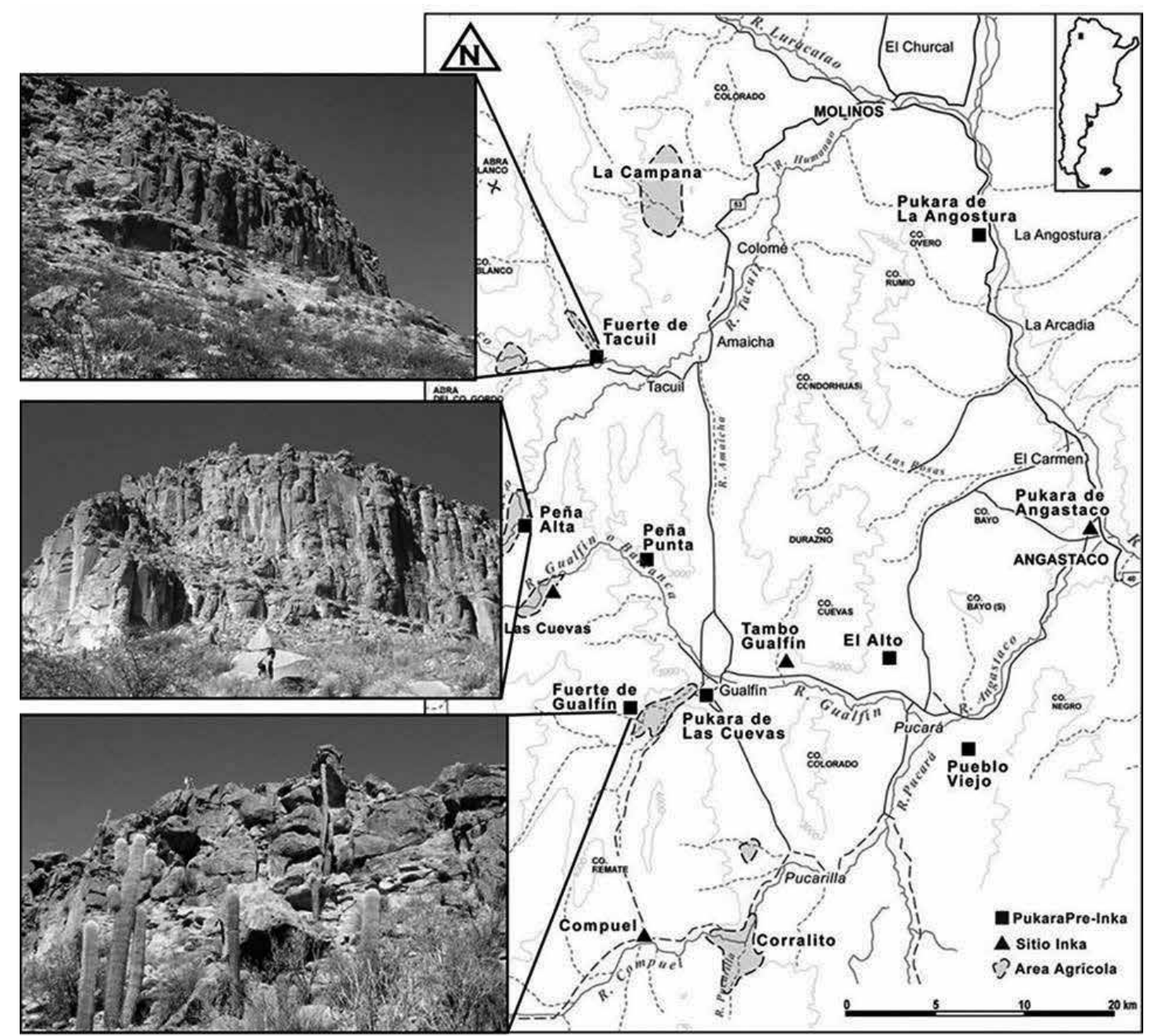

Figura 1. Mapa del valle Calchaquí medio (Salta) con sitios arqueológicos registrados. Tomado de Williams (2012).

pudiendo haber constituido geosímbolos o marcas en el paisaje hacia momentos de ocupación estatal, tomando protagonismo nuevamente durante las guerras Calchaquíes y la colonia temprana.

En el sector bajo estudio se destaca la vinculación espacial (aunque no sabemos si temporal) entre pukaras y espacios agrícolas (que abarcan una superficie aproximada de $350 \mathrm{ha}$ ), con estructuras para el manejo del agua, donde además se localizan grandes bloques rocosos con grabados de motivos abstractos, horadaciones o depresiones circulares u ovoidales (como en Peña Alta), motivos de líneas paralelas concéntricas tipo andenes (chacras o miniaturas de campos de cultivo) y diseños con forma de tumi, escutiformes y ancoriformes (como los de Quebrada Grande y Tacuil) (Williams et al. 2011).
En la base del afloramiento rocoso donde se localiza el fuerte de Tacuil existen varios bloques con grabados. Dos de ellos llamaron nuestra atención: uno con diseños de rostro/ máscara Aguada junto a uno con un personaje Formativo al que posteriormente dibujaron o grabaron un antropomorfo del Tardío (Williams y Villegas 2013).

La concentración de pukaras en las quebradas altas del Calchaquí medio nos sugiere un interés en controlar/defender ciertos espacios o territorios y sus pasos hacia la puna o los valles por parte de las poblaciones al menos durante el PDR (Villegas 2011, Williams 2010). Para el momento Inca la situación es diferente. La reconfiguración del paisaje durante este periodo se dio a partir de la instalación de sitios estatales sobre el fondo 
de valle troncal y el piso de puna, a la manera de marcadores en el paisaje (Williams 2012). Pero también los pukaras, los sitios con arte rupestre o ciertas rocas pudieron ser lugares continuamente resignificados (Williams 2012).

\section{Pukara o Fuerte de Tacuil}

El Fuerte Tacuil se emplaza en una quebrada lateral de la vertiente occidental del valle Calchaquí (Cigliano y Raffino 1975). Desde su ubicación se cuenta con un dominio visual sobre la confluencia de los ríos Blanco y La Hoyada, asociados a las abras de los cerros Gordo y Blanco, conexiones naturales hacia la puna. Localizado sobre una meseta dacítica de origen volcánico, presenta un acceso sumamente difícil, con una pendiente de casi 80 grados (Cigliano y Raffino 1975: 47). En la base del cerro hay estructuras y en la cima hay varios parapetos y conjuntos arquitectónicos muy bien conservados conformando un patrón semiconglomerado de recintos circulares y subrectangulares, agrupados en conjuntos arquitectónicos discretos (Villegas 2006). Se cuenta hasta el momento con un fechado de un contexto habitacional del fuerte (UGA 5939: $630 \pm 25 \mathrm{BP}$ ), el que concuerda con la hipótesis inicial de que el mismo correspondería al PDR (Williams 2012); aunque no se descarta una ocupación anterior ${ }^{3}$.

\section{Pukara de Gualfín}

El fuerte de Gualfín (0, 66 ha) (Figura 2) se localiza sobre un promontorio rocoso dacítico de difícil acceso, presenta excelente visibilidad hacia el norte y sur de la quebrada. Está formado por unos cuantos recintos conglomerados que presentan estructuras de planta circular e irregulares construidas en forma muy expeditiva (Villegas 2006). Sobre las laderas de la meseta se localizan recintos y murallas que llegan a medir hasta un metro de altura (Raviña et al. 1983: 864). Asociado espacialmente al fuerte se hallan cuadros y andenes de cultivo, además de bloques con grabados rupestres (Williams 2010). El fechado radiocarbónico del Fuerte (UGA 5939: $830+/-25$ BP) lo ubica en los inicios del PDR, aunque los datos históricos apoyan la idea de una larga ocupación.

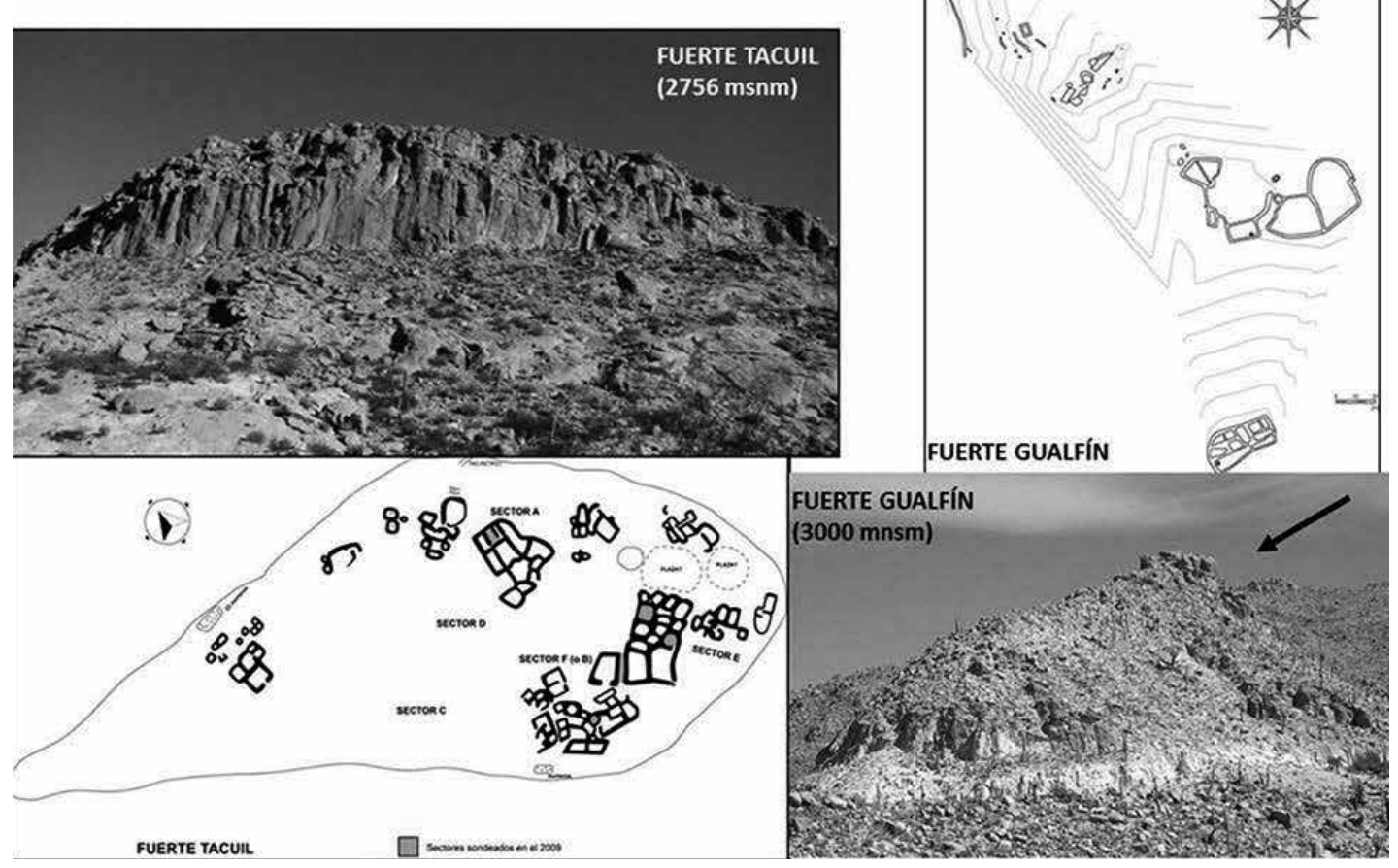

Figura 2. Imágenes y planos de los Fuertes de Tacuil y Gualfín. Gentileza de P. Villegas y V. Williams. 


\section{El valle de Luracatao: loma de Luracatao o Fuerte de Elencot}

Este valle (Figura 3) constituye una ramificación lateral del valle principal del río Calchaquí, representa una zona de transición entre las provincias geológicas de la cordillera Oriental y puna. Aquí los asentamientos arqueológicos se localizan en las terrazas inferiores del río y se caracterizan por ser sitios habitacionales de tipo conglomerado de planta rectangular, algunos en sectores altos con murallas de circunvalación y extensos aterrazados (Baldini y De Feo 2000). Recientes trabajos de campo permitieron registrar varios asentamientos, entre los que se destacan extensas áreas destinadas a actividades agrícolas (como el sitio El Duraznal o El Churquío canchones), conglomerados habitacionales (como Buena Esperanza y Cuchiyacu) y un asentamiento tipo pukara, conocido como El Fuerte o Loma de Luracatao (mencionado en las crónicas tempranas como Elencot). Este último está emplazado sobre una lomada elevada, por encima de $\operatorname{los} 40 \mathrm{~m}$ sobre el fondo de valle, espacialmente vinculado a los sitios Churquío canchones (hacia el oeste) y Buena Esperanza (al norte). Presenta tres líneas de murallas de piedra localizadas a lo largo de los faldeos oeste y sudoeste de la lomada. En la cima se pudieron registrar al menos 50 recintos de diferente tamaño y morfología. Se destacan las excelentes condiciones de visibilidad que se tiene hacia todo el valle, tanto de la llanura aluvial del río como el abra de los Diablillos, zona natural de comunicación con la puna. Hacia el sudeste del fuerte, sobre una elevación intermedia entre la cima y la base, se destaca un gran bloque rocoso que presenta recintos semicirculares adosados y que es considerado por la población actual como una huaca (Williams et al. 2013).

\section{La presencia incaica}

Las investigaciones realizadas permiten sugerir que los asentamientos estatales en este sector del valle son notablemente visibles en el paisaje representando posiblemente "un cambio en la estructura del paisaje local" (Williams 2010: 17). Aquí, Williams y Villegas (2013: 249) plantean una apropiación, por parte del estado inca, de espacios con ocupaciones e historia previa (algunos modificados arquitectónicamente y otros reocupados). Estrategia de incorporación que pudo estar acompañada por la legitimación de espacios en el transcurso de la memoria (Williams y Villegas 2013: 250).

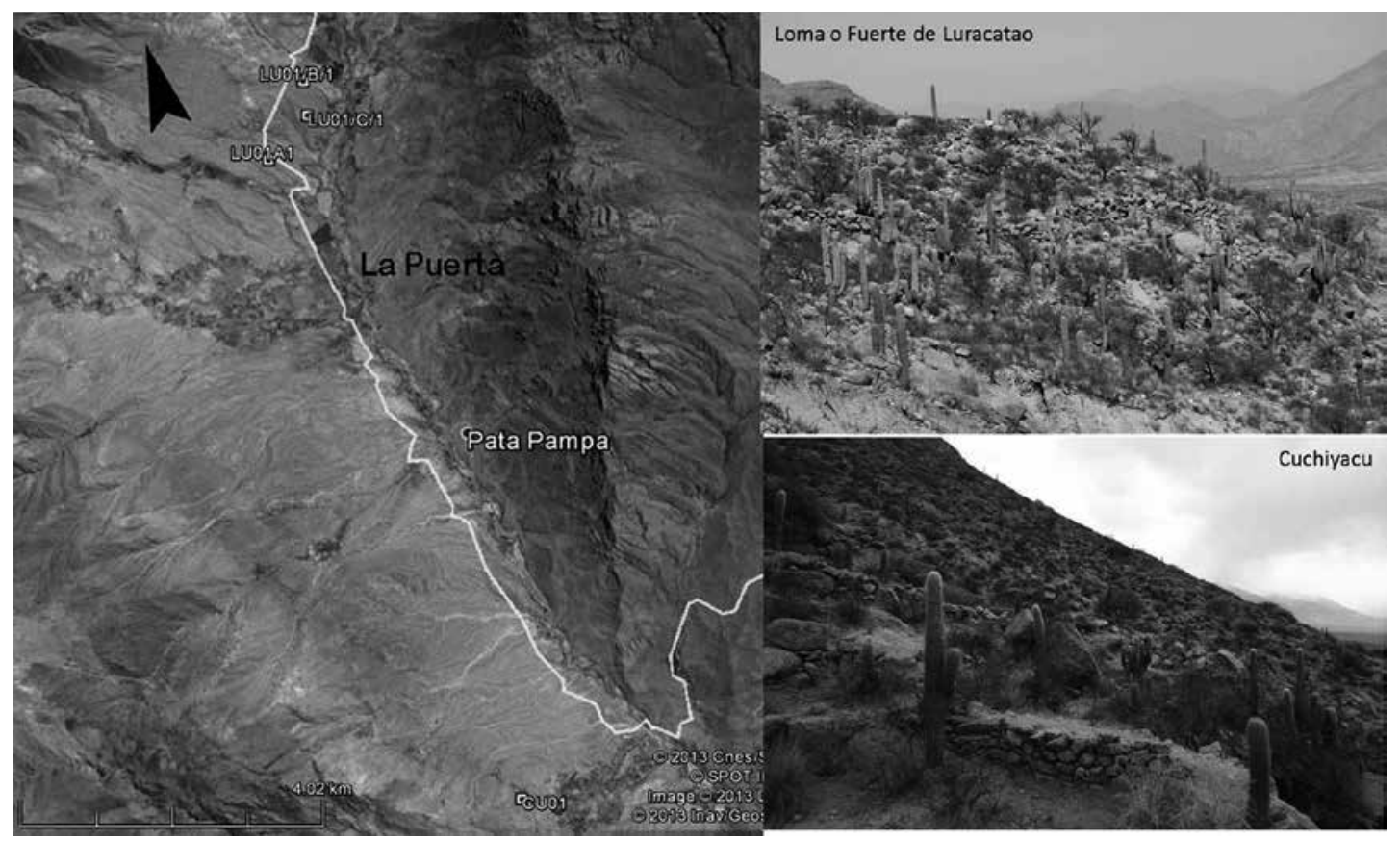

Figura 3. Valle de Luracatao: izquierda, imagen satelital con sitios registrados y mencionados en el trabajo; derecha, vista panorámica de los sitios LU01/C/1 y CU01. Fotografías de E. Benozzi y A. Capra. Tomado de Williams et al. 2013. 
La impronta Inca se manifiesta en el paisaje local a partir de sitios con arquitectura estatal y de un tipo especial llamados celdas o sitios para propósitos especiales (sensu de Hoyos y Williams 1994) en el sector alto del río Gualfín y en Compuel. Este tipo de estructuras tiene una distribución limitada en el área andina (Calahoyo, frontera con Bolivia; Las Cuevas IV, quebrada del Toro; Cortaderas, valle Calchaquí Norte, pampa Ciénaga, San Antonio, La Maravilla, Huasamayo, La Lagunita y Ranchillos, en Abaucán; valle del Cajón) (De Hoyos 2004). Debido a que la caracterización funcional de estas celdas está en discusión, las escasas excavaciones realizadas en $\mathrm{Compuel}^{4}$ permiten plantear actividades domésticas en los RPC desconociendo hasta el momento la función de las celdas (Williams y Villegas 2013). Dejando de lado su función material sostenemos que este tipo especial de planificación pudo ser una especie de "marca" o marcador estatal en el espacio (Williams
2010) (Figura 4). A partir de los trabajos llevados a cabo en la zona, Williams (2012) plantea que el estado Inca en las quebradas altas de las cuencas de Angastaco-Molinos haya orientado su interés en las quebradas altas en las áreas agrícolas, ampliándolas, construyendo andenes, terrazas, canales de irrigación, acueductos a partir del análisis formal y de una serie de fechados C14 de sectores agrícolas, específicamente del sedimento basal de los despedres (Korstanje et al. 2010) .

\section{El pukara de Angastaco}

El pukara de Angastaco, de clara factura inca, está ubicado sobre el valle principal a $1.900 \mathrm{msnm}$. De planta subcuadrangular (4.5 ha) está rodeado por una muralla perimetral con atalayas cuadrangulares (Raffino y Baldini 1983, Williams et al. 2005). En el sector central se pueden observar vestigios de estructuras circulares notablemente alteradas. Asociado a

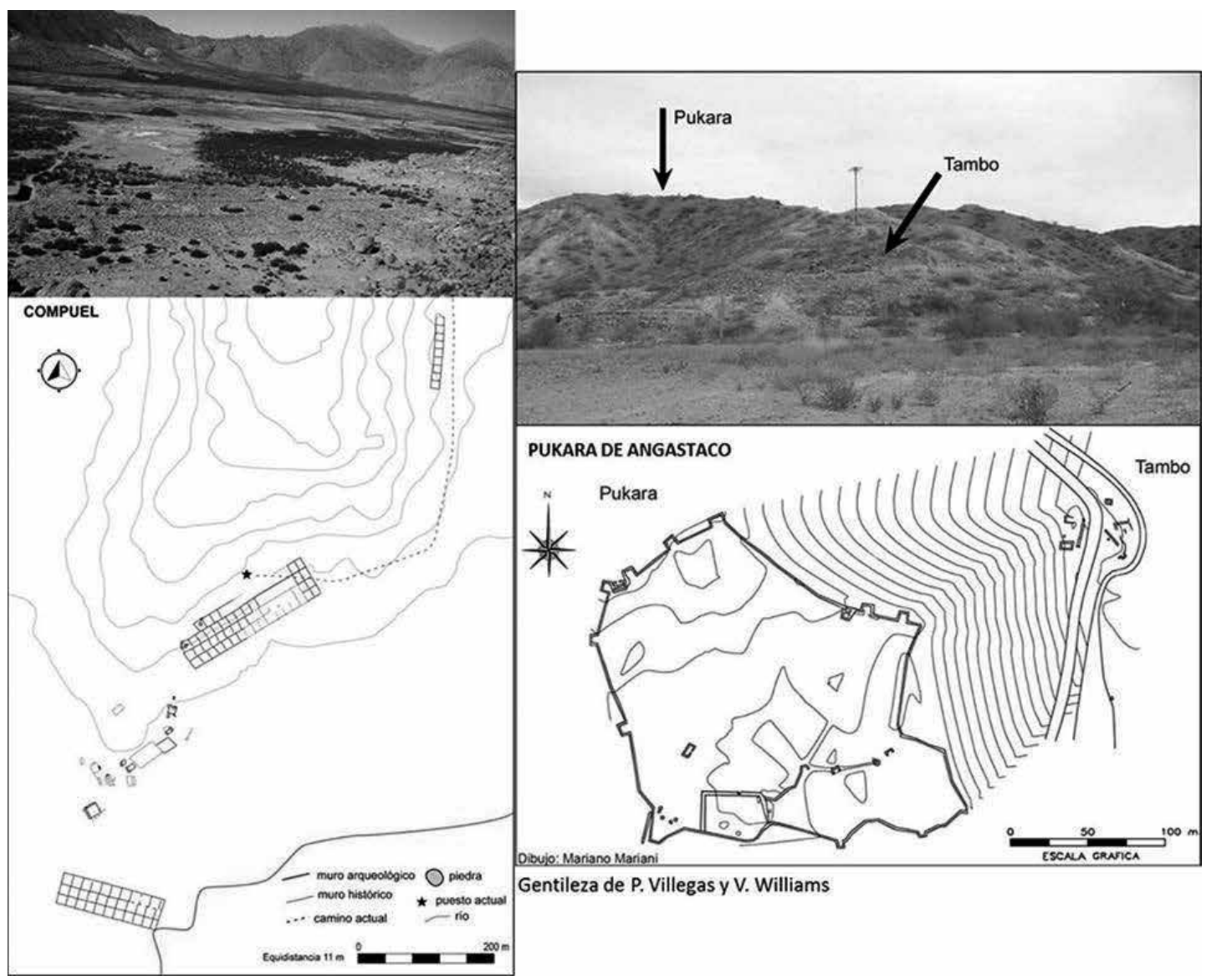

Figura 4. Imágenes y planos de los sitios Incas de Compuel y Angastaco. Villegas 2006: 72. 
este pukara, en el sector bajo, hacia el este, ruta 40 mediante, se halla un conjunto arquitectónico que corresponde a un tambo, lamentablemente en muy mal estado de conservación. Este sitio se destaca por la excelente visibilidad que presenta, al poder ser visto desde cualquier ángulo. Y este es un cambio radical con la lógica del paisaje del Tardío donde los pukaras están invisibilizados y, podríamos decir, mimetizados con el paisaje (Williams 2013).

\section{Urbina}

En cercanías del actual paraje de Isonza, valle de Amblayo, se emplazan estructuras que corresponden a recintos perimetrales compuestos (RPC) y celdas de factura inca similares a las localizadas en Compuel. Estas conforman lo que es conocido como el enclave estatal de Urbina, trabajado por M. de Hoyos (2004) (Figura 5). Trabajos recientes de prospección superficial permitieron reconocer al menos dos ocupaciones en el sitio, además de las reocupaciones actuales. Los recintos tipo celdas, de factura inca, mencionados por De Hoyos (2004) en general presentan notables alteraciones producto de los distintos usos a lo largo del tiempo. En estos grandes recintos se observó la presencia de cerámica de manufactura Inca en superficie. Mientras que en el sector alto del cono aluvial de la costa de Urbina

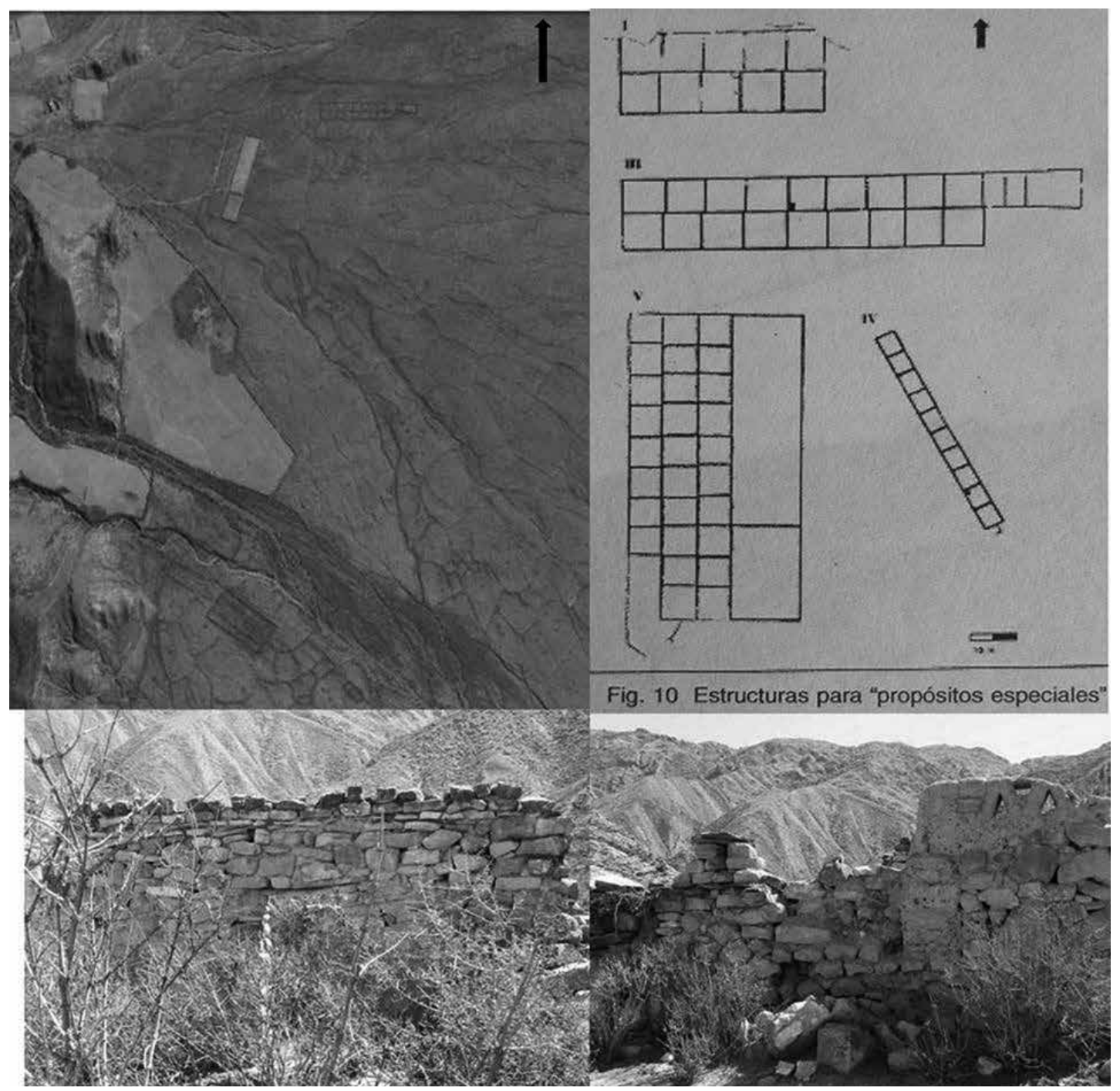

Figura 5. Arriba izquierda: imagen satelital del asentamiento de Urbina (tomado de Google Earth). Arriba derecha: detalle de estructuras para propósitos especiales. Tomado de M. de Hoyos (2004). Abajo: Urbina, imágenes de sector con ocupación histórica. 
se registraron estructuras con características constructivas de momentos históricos. Muros de adobe y piedra, junto a cerámica de manufactura local (estilo santamariano) e inca y loza hispana permiten plantear, de manera tentativa, esta posibilidad.

\section{Los aportes desde las fuentes históricas}

La información histórica destaca la presencia de distintas unidades étnicas a la llegada de los españoles, lo que llevó a plantear a este sector como un espacio multiétnico (Lorandi y Boixadós 1987-88). Una constante en las menciones es la existencia de fuertes, Albornoz (1637) menciona que los fuertes principales "que tienen estos pueblos rebeldes son doce, aunque cada pueblo tiene su fuerte que los resguarda... por estar cercanos entre sí se avisan dentro de una hora y se socorren los unos a los otros dentro de dos..." (Larrouy 1923: 260).

Hacia 1659 se inicia la primera campaña comandada por Mercado y Villacorta contra los Calchaquíes. En los Autos de esta campaña se señala que la cabecera del pueblo de los Taquigastas se hallaba en una quebrada tributaria de la de Humacatao, actualmente este asentamiento es conocido como Tacuil. Según las fuentes el ejército no llegó hasta el pueblo de Tacuil por estar fuera del camino habitual y además porque estos y los de Pompona salieron a ofrecerle la paz a los españoles (Lorandi y Boixadós 1987-1988). Sin embargo, en momentos posteriores, las poblaciones de Taquigasta participan activamente de los sucesivos levantamientos indígenas. Durante la última campaña de 1659 una carta del padre Torreblanca, fechada en 23 de noviembre de 1659, menciona la victoria conseguida con los Hualfines el día 14 de octubre y el asedio a los pueblos de Sicha, Pompona y Taquigasta, quienes a pesar de haber sido sacados de las montañas, regresaron a estos sitios. A diferencia de lo sucedido en las tierras de los Pulares y Luracataos, donde "fueron sacados todos" (Larrouy 1923: 234).

Gualfín, como categoría étnica y como lugar es mencionado y localizado en las fuentes en una quebrada tributaria de la de Angastaco o Gualfín. La documentación señala que estos grupos se hallaban estratégicamente asentados en un valle alto, en una fortaleza que fue asediada durante el último levantamiento (octubre de 1659), la que fue considerada como la "mas arriesgada Empresa del
Fuerte y Peñasco de Gualfín cuio ymposible fue benzido y echas prisioneras mas de ochozientas almas de esta parçialidad" (ABNB. Expedientes Coloniales. Año 1677, 20. Folio 40) $)^{6}$. Esta avanzada también fue narrada por el padre Torreblanca hacia 1696, quien señala que "todo el pueblo de Hualfín se había fortificado en un sitio, y fortaleza que formó la naturaleza, en medio de una montaña rodeada de peñascos [...]" (Torreblanca 1999 [1696]: 73).

Relatos mencionados en Matienzo (1910) [1567], la Relación Anónima Charcas 121 (citada en Lorani y Boixadós 1987-1988) y cartas del gobernador Ramírez de Velazco (1588), hacen referencia a un fuerte inca "llamado Angastaco, donde llegaron varios grupos indígenas de Calchaquí al mando de sus caciques en señal de paz" (AGI, Charcas 26, R 5 N17. Folio 5) ${ }^{8}$. Asentamiento localizado en un punto estratégico sobre el valle central, para Lorandi y Boixadós (1987-1988: 317) es posible plantearlo con un espacio multiétnico, ya que las fuentes mencionan que, entre otros, Gualfines y Sichas compartían terrenos en este sector.

Por su parte, Luracatao es mencionado en varias ocasiones en las cartas del gobernador Albornoz, en una de ellas hacia 1633 se menciona el avance sobre poblaciones "Luracataos, Sichagastas, Taquigastas, Gualfingastas, Animanaes y otros, que estaban confederados con los pueblos de los delincuentes" (carta del gobernador Albornoz 1633, en Larrouy 1923: 116). Las cartas relatan que fue necesario dar batalla a estos grupos alzados, el primero en ser atacado fue "Turacataos, metido y fortalecido en una gran serranía fragosa y áspera $y$ en su fuerte de Elencot de mucho nombre en aquellas partes" (carta del gobernador Albornoz 1633, en Larrouy 1923: 80).

Asimismo, un dato interesante señala que el pueblo de Luracatao estaba aliado con los grupos "matadores de Urbina" (Boixadós 2011: 98) ${ }^{9}$. La derrota de este pueblo fue fundamental, ya que permitió avanzar hacia otros sectores del Calchaquí. Una vez vencidos los Luracataos son reducidos y llevados al fuerte de Chicoana, en el norte del valle; avanzando posteriormente sobre los pueblos de Taquigasta y Sichagasta. Al parecer estos habían rechazado ya algunas propuestas de paz, ante ello $\mathrm{y}$ ante la presencia y apoyo de otros grupos, los españoles arremetieron contra este fuerte "por no aceptar la paz e irles entrando socorros de los pueblos comarcanos se les acometió a veinti y seis de diciembre al amanecer" (carta del gobernador 
Albornoz 1633, en Larrouy 1923). Esto permite considerar la posibilidad de la articulación de esta población con otras por medio de alianzas y preguntarnos si este tipo de relaciones se dan solo en momentos de guerra o si son vinculaciones de larga data. Finalmente se da el ataque del fuerte logrando quebrar la resistencia del pueblo de Luracatao y sus aliados, donde además de las bajas indígenas y la toma de prisioneros una cita del padre Torreblanca (23 de noviembre de 1659) sobre el asalto a "Umacathao" destaca la gran suma de grano y cantidad de legumbres, trigo, cebada y algarroba que se malbarató aquí.

Después de la batalla en Luracatao, el ejército español, unido a una porción que ingresó desde el sur, ajustició a los "indios delincuentes llamados de Malcachisco" por la muerte del encomendero Urbina, su cuñado y un fraile franciscano. En una carta del gobernador Albornoz de 1632 se menciona la salida de un grupo de españoles e indios amigos desde el fuerte de Calchaquí hacia el norte "para que al amaneser diesse ocho leguas de allí en los sitios de Acsivil y Payogasta por saver aver chacras en aquel paraje de los yndios de Malcachisco y Bonbolan donde se podrian azer algunos yndios descuidados" (BO ABNB ALP, CACh 940, 1634. Folio 4) ${ }^{10}$. Una vez realizada la avanzada hacia este asentamiento y vencidos los indígenas en Malcachivo, fueron liberadas las españolas cautivas y llevadas hacia Salta. La carta de Albornoz de 1634 a la que hacemos alusión señala que luego del asedio a poblaciones locales se realiza la salida del valle "por la misma parte que sentro en el, que fue por la estançia que llaman de Urbina, nunca hasta agora curssado que se elijio por la brevedad" (BO ABNB ALP, CACh 940, 1634. Folio 4). Siguiendo esta idea, Boixadós (2011: 98) menciona un ingreso a Calchaquí parando en las reducciones de pulares de Escoipe, luego la tropa siguió hasta lo que hoy es la cuesta del Obispo, pasó por la estancia de Urbina y por el pueblo de Tucumanahao. Asimismo, en una de las entradas que se hizo en 1658 se hace mención al levantamiento iniciado por Pedro Bohorques y sobre el avance español en la defensa de "dha frontera y [...] de la boca dela quebrada de Escoipe donde se formó el real y se hizo frente con campo a dhos enemigos y desde adonde subiendose con jente a la facçión de dha Estanzia de Urbina fue uno de las nombradas para ella..." (ABNB. Expedientes Coloniales. Año 1677, 20. Folio 47).
Para el caso de Urbina, teniendo en cuenta la particularidad del topónimo y la localización, nos preguntamos si cabe la posibilidad de que en este sector se hallara la hacienda del encomendero. La documentación permite ver que este fue un nexo fundamental para la entrada del ejército español desde el valle de Lerma, ya que tanto durante el segundo levantamiento como en el tercero el ingreso a Calchaquí se realizó por este lugar.

\section{Consideraciones finales}

Como reflexión final podemos decir que fue nuestra intención brindar una breve mirada acerca de la conformación del espacio en el sector medio del Calchaquí a lo largo de un lapso que abarca alrededor de tres siglos. La integración de fuentes nos permite sugerir una continuidad en la ocupación de las quebradas altas, por lo menos hasta el siglo XVII, siguiendo lógicas y prácticas propias de momentos prehispánicos. Bajo el contexto colonial, las tierras que corresponden a las quebradas altas son mencionadas como espacios de refugio indígena frente al asedio colonial. Para Quiroga (2010: 190) esta estrategia no podía ser el producto de una conducta desesperada, propia de una situación de peligro en la guerra, sino un recurso previsto y planeado para el que se plantea una profundidad temporal.

Las quebradas altas no son espacios distantes y de escaso interés para las ambiciones de los españoles. La importancia de las quebradas de acceso a la puna como áreas fértiles (además de espacios de conexión) queda evidenciada a partir de la existencia de grandes extensiones agrícolas materializadas en el paisaje. Una vez ya establecido el sistema colonial una tasación de 1802 sobre los bienes pertenecientes a la Hacienda de Calchaquí, publicada por Atilio Cornejo, destaca el potencial de esta área con "tierras excelentes para sembrar, y varios Huertos que logran por la mucha agua de pie permanente..." (Cornejo 1945: 427).

Respecto de las poblaciones de este sector, la información histórica destaca la presencia de distintas unidades étnicas a la llegada de los españoles, lo que llevó a plantearlo como un espacio multiétnico (Lorandi y Boixadós 1987-1988). Como ya mencionamos, las fuentes documentales permiten considerar que las tierras del fondo de valle formaban parte del territorio de las parcialidades Sichas; estas posiblemente se compartían también con poblaciones Gualfines (relación 
anónima Charcas 121 del AGI, citada en Lorandi y Boixadós 1987-1988). Esto último ¿permitiría sugerir la articulación y ocupación de distintos pisos altitudinales por parte de las poblaciones (por ejemplo en el caso de las poblaciones Gualfines)?

Desde la materialidad, podemos señalar que hasta el momento en la mayoría de los asentamientos de las quebradas altas que fueron investigados, a diferencia de Urbina por ejemplo, no se registraron objetos "de manufactura europea", aunque, en este sentido, mantenemos nuestras precauciones al momento de etiquetar manufacturas bajo un rotulo (prehispánico/ colonial, indígena/español), ya que en espacios tan complejos y complicados de abordar, como los coloniales tempranos, puede llevar a interpretaciones confusas. Como señala Quiroga (2007), los contextos arqueológicos que se plantean como representativos de ambas condiciones no siempre representan etapas diferentes, sino que podrían ser, inclusive, componentes de un mismo proceso colonial (Quiroga 2007: 96).

Nos queda avanzar en la búsqueda de elementos que nos permitan problematizar la idea del "vaciamiento" del valle posterior al último levantamiento, que estamos tratando de seguir en las fuentes. La información documental señala que inmediatamente después del último levantamiento se produjo el proceso de desnaturalización (hacia la segunda mitad del siglo XVII). El grueso de la población Calchaquí extrañada fue encomendada a vecinos del valle de Lerma (alrededores de la ciudad de Salta, Guachipas, Pulares), norte de valle de Siancas, sur de Jujuy y valle de Choromoros (Mata 2000). Posterior a este proceso se fueron conformando nuevas unidades productivas como estancias y haciendas. La principal hacienda del valle Calchaquí fue la de Molinos, la que surge a partir del otorgamiento de tierras a Diego Diez Gómez. Si bien muchas de las poblaciones indígenas desnaturalizadas se hallaban asentadas en otros espacios como parte de encomiendas, el regreso a Calchaquí, ya en el siglo XVIII, fue facilitado por los mismos encomenderos, ya que a muchos de ellos se les habían otorgado tierras en el valle (Mata 2000: 60). Esto sucedió, por ejemplo, para el caso de la Hacienda de Calchaquí, donde la población encomendada inicialmente se hallaba localizada en la quebrada de Escoipe y retornó al valle en las primeras décadas del siglo XVIII.

A futuro nos planteamos seguir trabajando respecto de la ocupación y conformación de aquellos espacios que tuvieron un papel fundamental en la articulación de las lógicas indígenas y española desde las fuentes documentales y arqueológicas (ocupaciones de momentos históricos para los sitios de Gualfín y Compuel). Continuamos en la búsqueda de indicadores que nos permitan sugerir las múltiples formas en que pudieron articularse relaciones, pero también elementos que aporten a la construcción de propuestas sobre la conformación y configuración de múltiples espacios en Calchaquí durante momentos coloniales tempranos, a través de relaciones, prácticas y tecnologías, entre otras. ${ }^{11}$

\section{Agradecimientos}

Una versión preliminar de este trabajo fue presentada en el Simposio "Diversidad y posibilidades en las Etnohistorias Andinas" del IX Congreso Internacional de Etnohistoria. Agradezco a los coordinadores de dicho simposio Dres. Lorena Rodríguez, Alejandra Ramos y Carlos Zanolli por la invitación a publicar y por haber creado un espacio ameno de diálogo e intercambio. Extiendo mi agradecimiento al Dr. Jorge Hidalgo, comentarista del simposio, por sus alentadores y enriquecedores comentarios. Al Arql. José Duglosz por su ayuda con las imágenes y a Paula Castellanos por ayudarme con las traducciones. Gran parte de los datos aquí presentados es producto de los trabajos realizados por el equipo de investigación dirigido por V. Williams, a quienes agradezco haber compartido esta información, en particular a Paula Villegas. Ninguno de ellos es responsable de lo aquí expresado. 


\section{Referencias Citadas}

Acuto, F.

1999 Paisaje y dominación: La constitución del espacio social en el Imperio Inca. En Sed non satiata. Teoría social en la arqueología latinoamericana contemporánea, editado por A. Zarankin y F. Acuto, pp. 33-75. Ediciones del Tridente, Bs. As. Acuto, F.

2007 Fragmentación vs. Integración comunal: Repensando el Período Tardío del Noroeste Argentino. Estudios Atacameños 34: 71-95.

Arkush, E. y C. Stanish

2005 Interpreting conflict in the Ancient Andes: implications for the archaeology of warfare. Current Anthropology 46 (1): 3-20.

Baldini, L. y De Feo, C.

2000 Hacia un modelo de ocupación del valle Calchaquí central (Salta) durante los Desarrollos Regionales. Relaciones de la SAA 25: 75-98. Buenos Aires.

Boixadós, $\mathrm{R}$

2011 Rebeldes, soldados y cautivos. Etnografía de un episodio en la frontera de guerra del valle Calchaquí (1634). En Resistencias, conflictos y negociaciones. El valle Calchaqui desde el período prehispánico hasta la actualidad, compilado por L. Rodríguez, pp. 93-122. Prohistoria Ediciones, Rosario.

Cigliano, E. y R. Raffino

1975 Arqueología en la vertiente occidental del valle Calchaquí Medio. Relaciones de la SAA 9: 47-56.

Cornejo, A.

1945 Propiedad Inmobiliaria de Salta en la Época Virreinal. Instituto San Felipe y Santiago de Estudios Históricos de Salta. Bs. As.

Cremonte, B. y V. Williams

2007 La construcción social del paisaje durante la dominación inka en el Noroeste Argentino. En Procesos sociales prehispánicos en el sur andino. La vivienda, la comunidad y el territorio. Compilado por A. Nielsen, C. Rivolta, V. Seldes, M. Vázquez y P. Mercolli, pp. 207-237. Editorial Brujas, Córdoba.

D'Altroy, T.; A.M. Lorandi, V. Williams, M. Calderari, C. Hastorf,

E. De Marrais y M. Hagstrum

2000 Inka rule in the Northern Calchaquí Valley, Argentina. Journal of field Archaeology 27: 1-26.

De Hoyos, $\mathrm{M}$

$2004 \mathrm{El}$ enclave incaico de Urbina, valle de Amblayo, Salta. Etnia 46-47: 331-352. Instituto de Investigaciones Antropológicas y Museo Etnográfico Dámaso Arce. Olavarría.

González, A. R.

1980. Patrones de asentamiento incaico en una provincia marginal del imperio. Relaciones de la SAA T. XIV, $\mathrm{N}^{\circ} 1$. Buenos Aires. Argentina.

González, L. y M. Tarragó

2005 "Vientos del Sur. El valle de Yocavil (Noroeste Argentino) bajo la dominación incaica". Estudios Atacameños 29: 67-97.

Larrouy, A.

1923 Documentos del Archivo de Indias para la historia del Tucumán. Tomo I. Buenos Aires.

Lorandi, A. y R. Boixadós

1987-1988 Etnohistoria de los valles Calchaquíes en los siglos XVI y XVII. Runa XVII-XVIII: 263-420. Buenos Aires, ICA, FFyL.UBA.
Lorandi, A.M. y M. De Hoyos

1995 Complementariedad económica en los Valles Calchaquíes y del Cajón, Siglos XV-XVII. En Colonización agrícola y ganadera en América siglos XVI-XVIII. Su impacto en la población aborigen. Coordinado por L. Escobari de Querejazu, pp. 385-414. Ediciones Abya Yala, Quito, Ecuador.

Mata de López, S.

2000 Tierra y poder en el Noroeste Argentino. Salta en vísperas de la Independencia. Colección Nuestra América. Editado por la Diputación provincial de Sevilla, España.

Montes, A.

1959 El gran alzamiento diaguita (1630-43). Revista del Instituto de Antropología 1: 81-159, Rosario.

Nielsen, A.

2002 Asentamientos, conflicto y cambio social en el Altiplano de Lípez (Potosí, Bolivia)". Revista Española de Antropología Americana 32: 179-205, Universidad Complutense, Madrid.

Nielsen, A.

2003 La edad de los Auca Runa en la Quebrada de Humahuaca (Jujuy, Argentina). Memoria americana 11: 74-107. Cuadernos de Etnohistoria. ICA, FFyL, UBA.

Nielsen, A.

2004 Pobres Jefes: Aspectos corporativos en las Formaciones sociales preincaicas de los Andes Circumpuneños. En Contra la Tiranía del pensamiento Tipológico en Arqueología: una visión desde Suramérica, editado por C. Gnecco y $\mathrm{H}$. Langebaek, pp. 120-150. Ediciones Uniandes. Universidad de los Andes. Bogotá, Colombia.

Nielsen, A. y W. Walker

1999 Conquista ritual y dominación política en el Tawantinsuyu: el caso de Los Amarillos (Jujuy, Argentina).En Sed non satiata: Teoría Social en la Arqueología Latinoamericana Contemporánea, editado por A. Zarankin y F. Acuto, pp. 153-169. Ediciones del Tridente, Buenos Aires.

Piazzini Suárez, C. E.

2006 Arqueología, espacio y tiempo: una mirada desde Latinoamérica. Arqueología Suramericana, editado por C. Gnecco y A. Haber, volumen 2, $\mathrm{N}^{\circ}$ 1: 3-25. Departamento de Antropología, Universidad del Cauca y Universidad Nacional de Catamarca.

Quiroga, L.

2007 Arquitectura de la vivienda prehispánica y colonial. Una perspectiva comparativa en el área valliserrana del Noroeste argentino. Actas del Congreso Internacional sobre Arquitectura vernácula en el mundo Ibérico, pp. 71-77. Coordinada por A. M. Aranda Bernal. Editado por la Universidad Pablo de Olavide, Sevilla.

Quiroga, L.

2010 En sus huaycos y quebradas: Formas materiales de la resistencia en las tierras de Malfín. Memoria Americana 18 (2): 185-209. Facultad de Filosofía y Letras, UBA.

Raffino, R. y L. Baldini

1983 Sitios arqueológicos del valle Calchaquí medio (Dep. Molinos y San Carlos). Estudios de Arqueología 3-4: 6-36. Museo Arqueológico de Cachi, Salta.

Raffino, R. A., L. Baldini, G. Raviña y A. Iácona 1979-1982 La expansión septentrional de la cultura La Aguada en el N. O. Argentino. Cuadernos del Instituto Nacional de Antropología (INAPL) № 9: 7-35. Buenos Aires. 
Raviña, M.G.; A. Iácona, y A. M. Albornoz

1983 Nota preliminar sobre una nueva fortaleza en el Valle Calchaquí: el Pukara de Gualfín. En Presencia hispánica en la Arqueología Argentina, Volumen 2, pp. 863-874. Museo Regional de Antropología e Instituto de Historia, Facultad de Humanidades, Universidad del Nordeste.

Ruiz, M. y M. E. Albeck

1997 El fenómeno pukara visto desde la puna jujeña. Estudios Atacameños 12: 83-95.

Sica, G.

2003 ¿De qué norte hablamos? Las percepciones históricas del espacio y sus consecuencias en la investigación de las sociedades prehispánicas y coloniales del noroeste argentino. Memoria Americana 11: 51-72. Facultad de Filosofía y Letras, UBA.

Strube Erdmann, L.

1958 La ruta de don Diego de Almagro en su viaje de exploración a Chile. Revista de la Universidad Nacional de Córdoba, número especial, $1^{a}$ parte: 270-293. Córdoba.

Tarragó, M.

2000 Chacras y Pukara. Desarrollos sociales tardíos. En Nueva Historia Argentina. Tomo I. Los pueblos originarios y la conquista. Editado por M. Tarragó, pp. 257-300. Editorial Sudamericana. Buenos Aires.

Torreblanca, Hernando de 1999 [1696] Relación Histórica del Calchaquí. Versión paleográfica de Teresa Piossek Prebisch. Archivo General de La Nación, Buenos Aires, Argentina.

Uhle, $\mathrm{M}$.

1912 Las relaciones prehistóricas entre el Perú y Argentina. En International Congress of Americanists, session XVII: 509-540. Buenos Aires.

Villegas, M. P.

2006. Teledetección arqueológica en el valle Calchaquí medio (Salta, Argentina). Tesis de Licenciatura, Departamento de Ciencias Antropológicas, Facultad de Filosofía y Letras, Universidad de Buenos Aires. Manuscrito sin publicar.

Villegas, M. P.

2011 Paisajes en movimiento. El uso del espacio durante los Períodos de Desarrollos Regionales e Inca en el valle
Calchaquí medio (Salta, Argentina). Estudios Sociales del $N O A$, en prensa.

Williams, V.

2008 Símbolos materiales y sistemas de representación del Imperio Inca en el NOA. En Lenguajes Visuales de los Incas, editado por T. Bray y P. González, pp. 43-51. BAR Internacional series. Sevilla.

Williams, V.

2010 El uso del espacio a nivel estatal en el sur del Tawantinsuyu. En El Hábitat Prehispánico, editado por M.E. Albeck, C. Scattolin y A. Korstanje, pp. 77-114. Facultad de Humanidades y Ciencias Sociales, Universidad Nacional de Jujuy, San Salvador de Jujuy.

Williams, V.

2012 Prácticas sociales del tardío prehispánico en las cuencas de Angastaco y Molinos (Salta, Argentina). Ponencia presentada en el 54 Congreso Internacional de Americanistas, University of Vienna.

Williams, V. y P. Villegas

2013 Colonización estatal en las cuencas de AngastacoMolinos (Salta, Argentina). En Al borde del Imperio. Paisajes sociales, materialidades y memoria en áreas periféricas del Noroeste Argentino, compilado por V. Williams y B. Cremonte, pp. 221-251. Publicaciones de la Sociedad Argentina de Antropología, Bs. As.

Williams, V. I.; Villegas, M. P.; Gheggi, M. S. y Chaparro, M. G. 2005 Hospitalidad e intercambio en los valles mesotermales del Noroeste Argentino. Encuentros: Identidad, Poder y manejo de espacios públicos, Boletín de Arqueología de la PUCP 9: 335-373. Lima, Perú.

Williams, V., C. Orsini y E. Benozzi

2013 Arqueología y paleoambiente en el valle Calchaquí Medio: Brealito y Luracatao. Informe Técnico presentado a la Dirección de Patrimonio Cultural de la Secretaría de Cultura y Turismo de Salta. Manuscrito en posesión de las autoras.

Williams, V.; A. Korstanje, P. Cuenya y M. P. Villegas

2011 La Dimensión Social de la Producción Agrícola en un Sector del Valle Calchaquí Medio. En Arqueología de la Agricultura: Casos de estudio en la región Andina Argentina, editado por A. Korstanje y M. Quesada, pp. 178-207. Ediciones Magna.

\section{Notas}

1 Para definir a este tipo de asentamiento seguimos la propuesta de Ruiz y Albeck (1997). Además, indistintamente mencionamos a los pukaras también como fuertes, ya que es la denominación que utiliza la población local actual.

2 Archivo General de Indias (AGI) y Archivo y Biblioteca Nacional de Bolivia (ABNB). La documentación del AGI fue consultada en el Portal de Archivos Españoles (PARES) http: //pares.mcu.es/

3 Rodolfo Raffino et al. (1972-1987) sugieren que este sector del Calchaquí sería el límite septentrional de Aguada, a partir del hallazgo de fragmentos cerámicos Aguada.

4 Sitio inca ubicado en una zona muy rica en pasturas, formado por un gran conjunto de rectángulos perimetrales compuestos y cuatro estructuras tipo celdas (sensu De Hoyos y Williams, 1994).

5 Despedres: Acumulaciones de piedras pequeñas y medianas, que son el producto de limpieza de los terrenos, y que en algunos casos forman parte de los tabiques de contención laterales de los andenes (Williams et al. 2011).

6 ABNB. EC año 1677, 20. 116 folios. Autos seguidos por don Pedro Martínez de Iriarte, pueblo de Tolombón en la provincia del Tucumán.

7 Este asentamiento es posteriormente también reconocido y mencionado por Max Uhle, ya hacia 1912.

8 AGI. Charcas 26, R5, N17. 1588 - Carta de Ramírez de Velazco y Luis de Hoyos sobre Calchaquí.

9 Recordemos que la muerte de Urbina en manos de grupos nativos fue un hecho relevante dentro del "Gran alzamiento" ante el descubrimiento de vetas minerales o metalíferas y por temor de la instalación de un centro de explotación minera (Montes, 1959).

10 BO ABNB ALP, CACh 940. Año 17/03/1634. Carta de Felipe de Albornoz, gobernador del Tucumán, a la audiencia de La Plata. Informa de las rebeliones de los indios de 
su provincia. Del socorro que proporcionó a los soldados del fuerte de San Bernardo en el valle de Calchaquí. De las acciones cometidas contra los enemigos, la muerte de varios caciques e indios importantes. Asimismo informa sobre las actuaciones y comportamiento de los vecinos de su provincia, en relación con los asuntos de guerra.

11 Este trabajo forma parte de un proyecto doctoral, actualmente en curso, financiado por una beca CONICET. 